
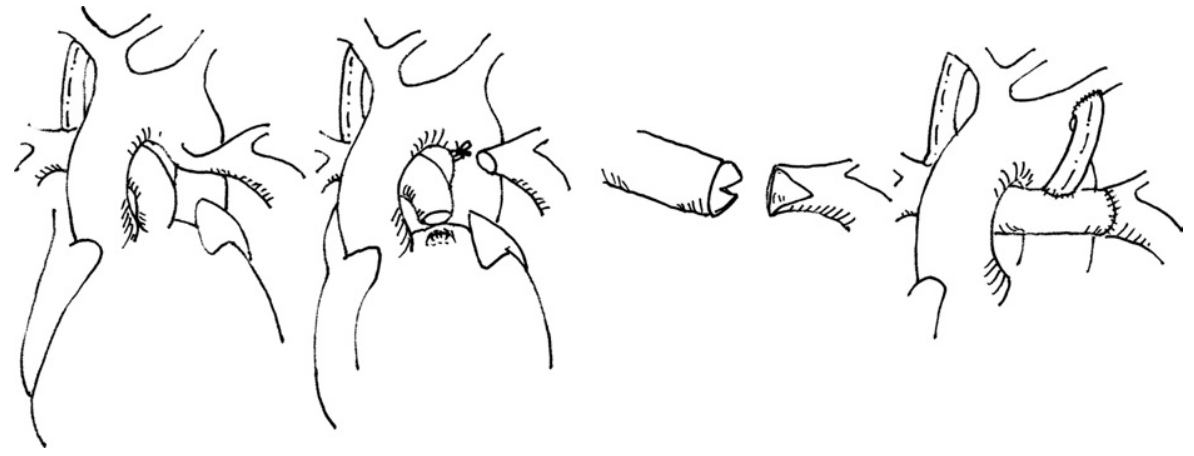

Figure 2. MPA translocation. MPA, main pulmonary artery.

patients with single ventricular morphology and a large enough MPA for translocation, because it might be difficult to reconstruct the right ventricular outflow tract for biventricular repair after this technique.

\section{Conclusions}

This technique is simple and applicable, providing excellent midterm results because of the continuity of autologous pulmonary arterial tissue.

\section{References}

1. Elzega NJ, von Suylen RJ, Frohn-Mulder I, Essed CE, Bos E, Quaegebeur JM. Juxtaductal pulmonary artery coarctation. An underestimated cause of branch pulmonary artery stenosis in patients with pulmonary atresia or stenosis and a ventricular septal defect. $J$ Thorac Cardiovasc Surg. 1990;100:416-24.

2. Oshima Y, Doi Y, Shimazu C, Misaki T. Left pulmonary arterioplastyextended end-to-end anastomosis. Ann Thorac Surg. 2005;79:1795-6.

\title{
Immunohistologic examination of pedicled autologous pericardium 9 years after implantation for an extracardiac conduit in Fontan pathway: Comparison with in situ pericardium and pulmonary arterial tissue from the same patient
}

Iki Adachi, MD, ${ }^{a}$ Hatsue Ishibashi-Ueda, MD, ${ }^{\text {b }}$ Toshikatsu Yagihara, MD, ${ }^{a}$

Koji Kagisaki, MD, ${ }^{\text {a }}$ Ikuo Hagino, MD, ${ }^{a}$ Toru Ishizaka, MD, ${ }^{a}$ and

Hideki Uemura, MD, FRCS, ${ }^{\mathrm{c}}$ Suita, Japan, and London, UK

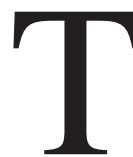

o date there have been no clinical reports, other than our own previous report, ${ }^{1}$ describing the histopathology of implanted pedicled autologous pericardium. Even in that report, a concern remains regarding whether the findings could correctly reflect the intrinsic properties of this

From the Departments of Cardiovascular Surgery a and Pathology, ${ }^{\mathrm{b}}$ National Cardiovascular Center, Suita, Japan; and the Department of CardioThoracic Surgery, Royal Brompton Hospital, London, UK.

Received for publication Dec 1, 2006; accepted for publication Dec 13, 2006.

Address for reprints: Toshikatsu Yagihara, MD, 5-7-1 Fujishirodai, Suita, 565-8565, Japan (E-mail: yagihara@hsp.ncvc.go.jp).

J Thorac Cardiovasc Surg 2007;133:1101-3

$0022-5223 / \$ 32.00$

Copyright $\odot 2007$ by The American Association for Thoracic Surgery doi:10.1016/j.jtcvs.2006.12.028 tissue, because the examined tissue had been situated in apparently abnormal circum-

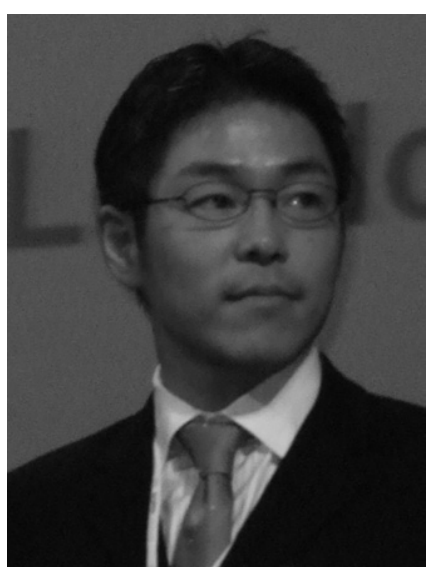

Dr Adachi stances in which a conduit constructed with the pericardium had been compressed and occluded. Fortunately, we obtained another pedicled specimen that had been quite functional in a Fontan pathway at the time of removal. The aim of this study was to confirm the histologic characteristics of the pedicled pericardium, comparing them with our previous findings.

\section{Clinical Summary}

The patient underwent primary Fontan operation with an extracardiac conduit made with pedicled autologous pericardial roll (PAPR) $^{2,3}$ at 1 year of age. At the operation, a small piece of pulmonary arterial tissue was obtained and adequately preserved for future histologic investigation. When the patient required reoperation to relieve subaortic stenosis at 10 years of age, pericar- 


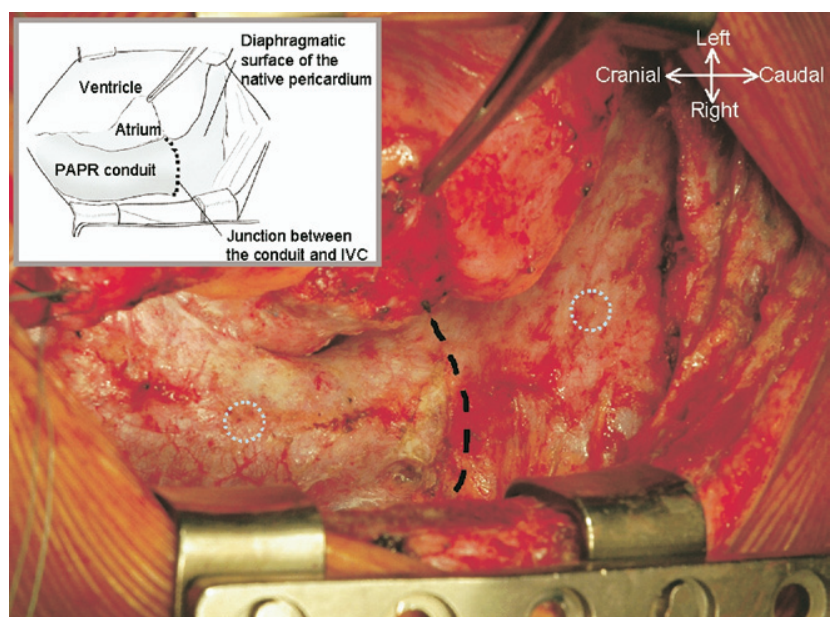

Figure 1. Intraoperative photograph: pericardial conduit and diaphragmatic surface of fresh pericardium were pink and pliable. Black dotted line indicates anastomotic site between pedicled autologous pericardial roll (PAPR) conduit and inferior vena cava (IVC); blue dotted circles indicate tissue sampling sites.

dial specimens, including both the PAPR tissue and the fresh in situ pericardium on the diaphragmatic surface, were collected (Figure 1). Institutional approval for the study was obtained, and the patient and his parents gave informed consent for tissue re- moval and subsequent investigations. These specimens were examined immunohistologically.

Elastica-van Gieson staining revealed a band of elastic tissue near the luminal surface of the PAPR tissue, whereas such a band was not observed at all in the fresh pericardial tissue. The elastic band was demonstrated more clearly in the pulmonary arterial tissue. The extent of microvasculature in the PAPR tissue shown on factor VIII staining was almost identical with that of the fresh pericardium. Staining for factor VIII also yielded positive cells, confirming the presence of endothelium on the luminal surface of the PAPR conduit (Figure 2). Neither calcification nor fibrosis was observed on hematoxylin-eosin staining.

\section{Discussion}

The largest difference between the previous study and this one is the situation in which the PAPR tissue was obtained. Obviously, when attempting to elucidate natural properties of some tissues, it is better to use tissues from a normal situation. In this regard, the specimen in this study is of particular value.

In our previous report, ${ }^{1}$ we demonstrated four major findings: (1) preservation of microvasculature, (2) presence of a band of elastic tissue, (3) presence of endothelium on the luminal surface, and (4) absence of either calcification or fibrosis in the PAPR tissue. Of these, preservation of microvasculature is of significant importance with respect to growth ability, because tissue viability is a fundamental element for growth. In this study, both presence and equivalent density of the microvasculature were demonstrated by comparison with the fresh in situ pericardial tissue. As we

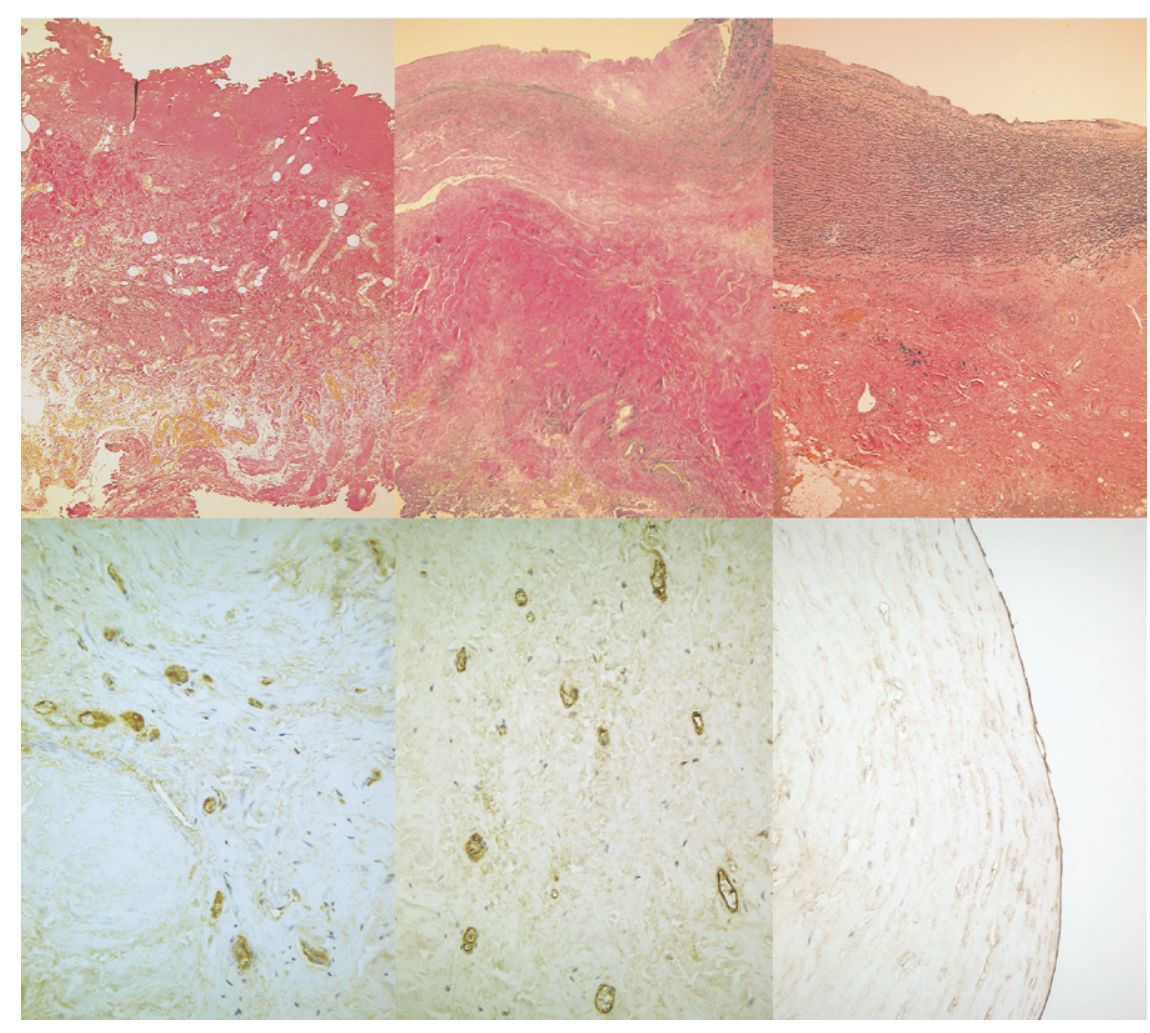

Figure 2. Elastica-van Gieson staining (original magnification $\times 10$ ) revealed band of elastic tissue near luminal surface of pedicled autologous pericardial roll tissue (upper middle) and pulmonary arterial tissue (upper right), whereas such elastic band was not observed at all in fresh pericardial tissue (upper left). Staining for factor VIII (original magnification $\times 20$ ) showed extent of microvasculature in pedicled autologous pericardial roll tissue (lower left) to be almost identical to that in fresh pericardial tissue (lower middle). Staining for factor VIII (original magnification $\times 10$ ) yielded positive cells, confirming presence of single layer of endothelial cells on luminal surface of pedicled autologous pericardial roll conduit (lower right). 
described previously, ${ }^{1}$ the density is clearly greater than that in the implanted, nonpedicled pericardium. Preserved microvasculature and glossy appearance of the PAPR conduit can reasonably be considered to be the result of maintenance of pericardial pedicle and to indicate preservation of viability.

Such comparison between the two different pericardial tissues was also useful when evaluating the extent of the band of elastic tissue. As shown in the photograph of the pulmonary arterial tissue, such a band is generally found in the vascular wall tissue, not in the normal pericardium. The layer of the developed elastic band in the PAPR tissue would suggest remodeling of the channel wall, in which the pedicled pericardium has transformed from its norm to the structure of the vascular wall after having been used for that purpose. The remaining two original findings (presence of endothelium and absence of calcification and fibrosis) were also confirmed in this study. Considering these findings together, PAPR seems to be a suitable material as a vascular substitute, at least for a lowpressure chamber such as the Fontan pathway.
In conclusion, the PAPR remained viable and even had obtained some characteristics similar to vascular wall 9 years after implantation for the Fontan pathway.

We thank Dr Yusuke Shimahara for his contribution in the intraoperative photograph.

\section{References}

1. Adachi I, Yagihara T, Ishibashi-Ueda H, Kitamura S. Immunohistological findings for an extracardiac conduit in Fontan pathway constructed with pedicled autologous pericardium. Eur J Cardiothorac Surg. 2006; 29:1059-60.

2. Uemura H, Yagihara T, Kawahira Y. The extracardiac Fontan procedure using a pedicled pericardial roll without cardiopulmonary bypass. J Thorac Cardiovasc Surg. 1999;117:1046-7.

3. Adachi I, Yagihara T, Kagisaki K, Hagino I, Ishizaka T, Koh M, et al. Fontan operation with a viable and growing conduit using pedicled autologous pericardial roll: serial changes in conduit geometry. $J$ Thorac Cardiovasc Surg. 2005;130:1517-22.

\section{Closure of tracheogastric fistula by video-assisted tracheoscopy, direct repair, and self-expandable titanium stent in a patient with total laryngopharyngoesophagectomy}

Said Fayoumi, MD, and Samer Sawalhi, MD, Amman, Jordan

Video clip is available online.

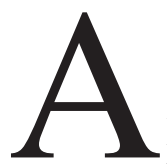

fistula between the trachea and an oseophagogastric anastamosis after oseophagectomy is uncommon. ${ }^{1}$ An alternative means of reconstruction after laryngopharyngo-oseophagectomy should be considered. $^{2}$ Kalm'ar and associates ${ }^{3}$ used the pectoralis major muscle flap to prevent recurrence of the fistula. The advent of video-assisted

From King Hussein Cancer Center, Department of Surgery, Amman, Jordan.

Received for publication Aug 3, 2006; accepted for publication Oct 23, 2006.

Address for reprints: Said Fayoumi, MD, Department of Surgery, King Hussein Cancer Center, Amman, Jordan (E-mail: Fayoumi@gmail.com).

J Thorac Cardiovasc Surg 2007;133:1103-4

$0022-5223 / \$ 32.00$

Copyright $\odot 2007$ by The American Association for Thoracic Surgery doi:10.1016/j.jtcvs.2006.10.041 technology provided an effective, definitive, and one-stage repair of tracheogastric fistula (TGF).

\section{Clinical Summary}

A 33-year-old man was known to have squamous cell carcinoma of the hypopharynx, to have hypertension, and to be a smoker. He reported dysphagia, weight loss, and hoarseness. An endoscopic examination of the upper gastrointestinal tract showed stenotic stricture at the cricopharyngeal junction. The biopsy result was moderately differentiated squamous cell carcinoma.

The patient underwent 28 fractions of radiotherapy and 25 sessions of chemotherapy (5-fluorouracil and cisplatin), then total laryngectomy, pharyngectomy, esophagectomy and gastric pull-up (transhiatal approach). He was discharged in good general condition.

Three months later, the patient was admitted via the casualty department with shortness of breath, choking, and coughing, especially with water, after meals. Because TGF was suspected, an examination with a rigid bronchoscope was performed, which disclosed TGF at the upper membranous part of trachea (Figure 1). A biopsy specimen was negative for tumor.

The TGF was closed directly through video-assisted thoracic surgery (VATS) by 2-0 Vicryl polyglactin 910 sutures reinforced by insertion of a self-expandable titanium stent (see video). Five days later, the patient was readmitted with recurrence of the fistula. The stent was removed and the fistula resutured by VATS, taking 